MedieKultur | Journal of media and communication research | ISSN 1901-9726

Book Review

\title{
Tonny Krijnen \& Sofie Van Bauwel: Gender and Media: Representing, Producing, Consuming. New York: Routledge. 2015.
}

\author{
Kelechi Amakoh
}

MedieKultur 2020, 67, 141-143

Published by SMID | Society of Media researchers In Denmark | www.smid.dk The online version of this text can be found open access at https://tidsskrift.dk/mediekultur

The media landscape of today is greatly influenced by the increasing wave of globalization and ever-changing new media technologies. These guiding factors help to understand the intersection between media and other related concepts in the 21st century. In Tonny Krijnen and Sofie van Bauwel's book, Gender and Media: Representing, Producing, Consuming, these factors are taken into consideration in the discussion of the media's intersection with gender. The authors look at this intersection through the lenses of media representation, production and consumption of media content.

Krijnen and van Bauwel offer their viewpoint to the age-long debate about gender and media discourse. Specifically, from the outset the authors pursue the goal of providing a safe space for readers to arrive at their conclusion about the kind of connection that exists between media and gender (p. 2), and the authors' ambitious aim is to provide an understanding of the relationship between the media and gender (p. 4).

To achieve this overarching goal, the authors present an overview of the aspects related to gender and the media: representation, production and consumption. The focus on these aspects help provide a nuanced understanding of the relationship in gendered media and fills a gap in scholarship.

Gender and Media highlights the faint borders that exist between representation, production and consumption of gendered media content. Throughout the nine chapters of the book, the authors show how these faint borders are continually shrinking as a result of advancement in media technology and globalization. 
On gender representation, the authors focus on three concepts: subjectivity, subject positions and identity. They draw on scholars such as Stuart Hall, Jacques Lacan and van Zoonen to help unpack these concepts. In doing so, they surmise that the interaction between issues of subjectivity, subject positions and the identity of a person makes the concept gender fluid. The fluidity of gender representation is a result of the disruption tool known as intertextuality (p. 62). Using Lady Gaga and her music as an example, the authors argue that there is a multiplicity of gendered meanings displayed through her dressing, music videos, lyrics and personality.

According to the authors, intertextuality leads to the disruption of the masculinity/femininity dichotomy and gives rise to queer theorists. These theorists advance the notion of identification of several identities beyond the binary gender (p. 65). However, this call for a look beyond binary gender is yet to gain the traction it deserves. Specifically, the Western world remains the only area that has incorporated the concept (p. 72). The understanding of gender representation is normative and ambiguous (p. 44) and must be seen from a holistic context to make sense (p. 71). In the first three chapters, Krijnen and van Bauwel posit that gender representation in the media is a result of several intervening factors such as media convergence, transnationalization of the media, and development in media technology, thereby leading to a Western gendered representation across the globe (p. 49).

The authors dedicate chapters 4-6 to the ongoing discourses on media production and gendered content. The authors dedicate three chapters of the book to this discussion and offer their contribution. One popular discourse is the glass ceiling in the mediasphere. According to the authors, the concept is "vague" (p. 94) and "loosely used" (p. 95). Drawing on available scholarly texts, the authors argue that on top of gender inequality, glass ceiling causes ethnic inequality (p. 95).

The authors also Juxtaposes the concept of the glass ceiling with the concept of the sticky floor. On one hand, the glass ceiling factors such as class, disability, sexuality and ethnicity limits ascendancy on professional ranking. On the other hand, the concept of the sticky floor acknowledges the fact that women are promoted just as much as men but are paid less for the same job (p. 96).

With the invisible ceiling yet to be fully removed, the authors note that the advancement of new media technologies has rejigged the concept of production. This has brought about a democratic process in media production, thereby allowing the once passive audience to be active content creators. However, recent studies show how these technological innovations promote the male hegemonic order thereby causing a gender imbalance in the creation of User Generated Content (p. 119). The male hegemonic order reinforced by the advancement in media technology highlights the deep-seated imbalance between gender and media. It remains to be seen when women will be seen as "producers" (p. 110) of media content and not only consumers. 
The last three chapters focus on consumption. The authors discuss two concepts in the discourses on gender and media: sexualization and pornofication. According to the authors, sexualization aims to connect everything trending in society - clothes, music with sex. On the other hand, they define pornofication as "slightly less trendy" (p. 159). These concepts as discussed in the book highlight how complex gendered media are today. The authors, therefore, advocate for the inclusion of the voices of women and girls in this discourse. They premise their advocacy on the fact that women and girls are the ones at risk of a highly sexualized and pornoficated media (p. 164).

Krijnen and van Bauwel draw upon numerous concepts related to gender and media situated upon two influential and overarching standpoints: globalization and new media. A downside to this is the minimal exploration of these concepts in the book. On the other hand, suggestions for further reading after every chapter and the provision of interactive text boxes within the chapters help cover the book's downside.

Gender and Media: Representing, Producing, Consuming provides a critical angle to discourses on gender and media. The authors provide an understanding of the complex "relation between gender and media and its complications" ( $p$. 14). Within the nine chapters of the book, the authors strive to achieve this goal with considerable success in spite of the complexities of gender and media discourse.

This book creates a safe space (p. 2), as aimed for by the authors, for a reader to make an informed position in the discourse of gender and media. As envisioned by the authors, the book provides a balanced view and empowers the reader with the needed tools to form their opinion on ongoing debates about gender and the media (p.14). This book should make the reading list of students, researchers and teachers as well as advocates of gender and media.

Kelechi Amakoh

Graduate Student School of Communication and Culture Aarhus University, Denmark 